\title{
Is Treatment Inertia Unique to Publicly Funded Healthcare? Insights from the Guidelines Oriented Approach to Lipid lowering (GOAL) Canada
}

\section{Program}

Anatoly Langer ${ }^{1 *}$, Shaun G. Goodman ${ }^{1,2}$, G. B. John Mancini ${ }^{4}$, Mary Tan ${ }^{1}$, Jean Grégoire ${ }^{3}$, Peter J. Lin ${ }^{1}$, James A. Stone ${ }^{5}$, Lawrence A. Leiter ${ }^{6}$

${ }^{1}$ Canadian Heart Research Centre

${ }^{2}$ St Michael's Hospital, University of Toronto, Toronto, Ontario, Canada

${ }^{3}$ Université de Montréal, Institut de cardiologie de Montréal

${ }^{4}$ University of British Columbia

${ }^{5}$ Cumming School of Medicine, University of Calgary; Libin Cardiovascular Institute of Alberta

${ }^{6} \mathrm{Li}$ Ka Shing Knowledge Institute, St. Michael's Hospital, University of Toronto, Toronto, Canada

*Corresponding Author: Anatoly Langer, Canadian Heart Research Centre

Received Date: March 22, 2021; Accepted Date: April 01, 2021; Published Date: April 08,2021

Citation: Anatoly Langer, Shaun G. Goodman, G. B. John Mancini, Mary Tan, Jean Grégoire., et al (2021) Is Treatment Inertia Unique to Publicly Funded Healthcare? Insights from the Guidelines Oriented Approach to Lipid lowering (GOAL) Canada Program. J. Clinical Cardiology and Cardiovascular Interventions, 4(7); Doi:10.31579/2641-0419/154

Copyright: () 2021 Anatoly Langer, This is an open-access article distributed under the terms of the Creative Commons Attribution License, which permits unrestricted use, distribution, and reproduction in any medium, provided the original author and source are credited.

\begin{abstract}
Background: We compared the use of lipid lowering therapy, low density-lipoprotein cholesterol (LDL-C) levels, and proportion achieving guideline-recommended LDL-C levels in patients with private vs. public insurance coverage for their lipid lowering treatment.
\end{abstract}

Materials and Methods: Guidelines Oriented Approach to Lipid lowering (GOAL) Canada enrolled 2009 patients with cardiovascular disease (CVD) or heterozygous familial hypercholesterolemia (FH) and an LDL$\mathrm{C}$ above the guideline-recommended target of $<2.0 \mathrm{mmol} / \mathrm{L}$ despite maximally tolerated statin therapy. During two follow-up visits physicians received online reminders of treatment recommendations.

Results: Of 2009 patients enrolled (median age 63 years, 42\% female), there were 1284 (64\%) patients with private and 725 (36\%) with public insurance for lipid lowering therapy. Patients with private insurance were younger and less likely to have a history of heart failure or to be on bile acid sequestrants. There was no difference between the groups in their lipid levels or lipid lowering therapy at baseline. During the follow up, there was no difference in the use of ezetimibe; however, the use of PCSK9i was more frequent in patients with private insurance $(31.7 \%$ vs. $21 \%, \mathrm{p}<0.0001)$, the mean LDL-C level was slightly lower $(2.11 \pm 1.17$ vs. $2.31 \pm 1.17 \mathrm{mmol} / \mathrm{L}, \mathrm{p}=0.001)$, and the proportion of patients achieving the guideline-recommended LDL-C level was greater $(54 \%$ vs. $45.5 \%, \mathrm{p}=0.001)$. After adjustment for other factors in a multivariable model, private insurance was not a significant predictor of achieving the guideline-recommended LDL-C level in a multivariable model.

Conclusion: While PCSK9i use was higher in patients with private insurance, the majority of patients with either private or public insurance experienced similar treatment inertia. The cost of non-generic medications does not appear to be the dominant reason for the continued care gap in lipid lowering of high-risk patients.

Keywords: cardiovascular disease; familial hypercholesterolemia; Cardiovascular Medications

\section{Introduction}

Low-density lipoprotein cholesterol (LDL-C) level is a well-established risk factor for cardiovascular disease (CVD) and there is considerable evidence that lowering LDL-C reduces CVD morbidity and mortality. [1] Canadian Cardiovascular Society dyslipidemia guidelines [2] recommend initiation of LDL-C lowering with high intensity statin therapy with the addition of ezetimibe and / or PCSK9i as needed if LDL-C is not lowered by at least $50 \%$ or to the level below $2.0 \mathrm{mmol} / \mathrm{L}$ in patients with established CVD. Further, for those with a recent acute coronary syndrome and established coronary disease, consideration is to be given to more aggressive lowering of LDL-C to below $1.8 \mathrm{mmol} / \mathrm{L}$. [2] 
Nonetheless, strategies for lowering LDL-C are often poorly adopted in clinical practice, and many patients fail to reach guideline-recommended levels [4-8]. We have recently reported [9] that physician education based on a reminder approach imbedded into clinical practice, improves care significantly as measured by a higher proportion of patients achieving guideline-recommended LDL-C level in association with greater utilization of lipid lowering therapies.

This analysis explores whether patients with private insurance coverage and greater access for lipid lowering therapy experience achievement of recommended LDL-C level more frequently than those patients with public insurance only.

\section{Materials and Methods}

The Guidelines Oriented Approach to Lipid lowering (GOAL) Canada [9] was a medical education interventional program supported by Amgen Canada. It was an investigator-initiated study started in 2015 and coordinated by the Canadian Heart Research Centre, an academic research and physician education organization. The intervention studied was physician education based on lipid management reminders applied at the end of each of three visits based on data entry in an electronic case report form (eCRF) and the primary endpoint was proportion of patients achieving recommended LDL-C level of $<2.0 \mathrm{mmol} / \mathrm{L}$ in those with CVD and $<2.5 \mathrm{mmol} / \mathrm{L}$ or $\geq 50 \%$ reduction in those with heterozygous familial hypercholesterolemia (FH). All patients were recommended lifestyle modifications including dietary as recommended by the Canadian guidelines. [2] The study was approved by central and institutional research ethics boards where appropriate and all enrolled patients provided informed consent.

Invitations to participate were sent to a convenience sample of 750 Canadian physicians across Canada from a proprietary (CASL Regulation) Canadian Heart Research Centre list of physicians who participated in prior cholesterol-oriented data collection studies and 248 agreed to participate. The participating physicians had the primary and exclusive role in the management of their patients and selection of cholesterol lowering therapies. These physicians were asked to consecutively enrol at least 12 of their patients with either [1] clinical CVD including coronary artery disease (CAD), cerebrovascular disease, abdominal aortic aneurysm, or peripheral arterial disease; or, [2] FH. 2 Current use of PCK9i or prior participation in GOAL Program were the only exclusion criteria [9]. In addition, patient enrolment was allocated such that $2 / 3$ of the patients were required to have private insurance and $1 / 3$ public insurance only. All patients had to have [9] an LDL-C > 2.0 $\mathrm{mmol} / \mathrm{L}$ despite maximally tolerated statin therapy (defined as having tried at least two statins, each at least on two reduced doses) for at least three months prior to enrolment. Lipid lowering treatment was assessed on enrolment (visit 1) and twice more during follow up, each approximately 4-6 months apart (visits 2 and 3). The medical education intervention consisted of physician reminders to follow Canadian guideline recommendations [2] at each visit; physicians were also asked to provide reason when guidelines were not followed.

\section{Statistical Analysis}

Continuous data are shown as means with standard deviation and categorical data as frequencies and percentages. Group comparisons were made using the chi squared test and test or Kruskal-Wallis test for discrete and continuous variables, respectively, where appropriate. We used repeated measures analysis to perform univariate and multivariable regression to determine the outcome across the visits.

A multivariable logistic regression model was developed to assess factors independently associated with LDL-C achieving target (2) of $\leq 2.0 \mathrm{mmol}$. The following variables were considered: variables in Table 1 with $\mathrm{p}$ $<0.05$, type of insurance, use of statin, ezetimibe and PCSK9 inhibitor. To account for the clustering of patients within visits, we performed a generalized estimating equations (GEE) model. The working correlation structure selected was based on its lowest quasi-likelihood under the independence model criterion (QIC). Adjusted odds ratio (OR) with 95\% confidence intervals (CI) are presented. A value of $\mathrm{P}<0.05$ was considered significant for all tests except group comparison in Table 1 where correction for multiple $(\mathrm{n}=31)$ comparisons was applied and value of $\mathrm{P}$ $=0.002$ or less was considered significant. All statistical analyses were performed in SAS software version 9.4 (SAS Institute, Cary, NC).

\section{Results}

Of 2009 patients enrolled (median age 63 years, $42 \%$ female), there were $1284(64 \%)$ patients with private insurance and $725(36 \%)$ with public insurance only. Patients with private insurance were younger and less likely to have history of heart failure or to be on bile acid sequestrants (Table 1). There was no difference in LDL-C level between the two groups and no difference in the use of statin, including high intensity statin, or ezetimibe at baseline (Table 1).

\begin{tabular}{|l|c|c|c|}
\hline Variables & Private (N=1284) & Public (N=725) & p \\
\hline Age, years* & $62 \pm 11$ & $65 \pm 11$ & $<.0001$ \\
\hline Sex, female & $519(40 \%)$ & $326(45 \%)$ & 0.05 \\
\hline Caucasian/White & $921(72 \%)$ & $505(70 \%)$ & 0.33 \\
\hline Systolic Blood Pressure, $\mathrm{mm} \mathrm{Hg}^{*}$ & $129 \pm 15$ & $129 \pm 16$ & 0.96 \\
\hline Diastolic Blood Pressure, $\mathrm{mm} \mathrm{Hg}^{*}$ & $77 \pm 10$ & $76 \pm 10$ & 0.10 \\
\hline Heart rate, beat/minute* & $72 \pm 11$ & $73 \pm 11$ & 0.67 \\
\hline Body Mass Index, kg/m ${ }^{*}$ & $29.8 \pm 7.0$ & $29.1 \pm 6.1$ & 0.02 \\
\hline Coronary artery disease & $641(50 \%)$ & $395(54 \%)$ & 0.05 \\
\hline Cerebrovascular disease & $103(8 \%)$ & $62(9 \%)$ & 0.68 \\
\hline Abdominal aortic aneurysm & $23(2 \%)$ & $15(2 \%)$ & 0.66 \\
\hline Peripheral arterial disease & $110(9 \%)$ & $73(10 \%)$ & 0.26 \\
\hline Microvascular disease & $52(4 \%)$ & $36(5 \%)$ & 0.34 \\
\hline Familial hypercholesterolemia & $614(48 \%)$ & $341(47 \%)$ & 0.74 \\
\hline Current or past history of smoking & $600(47 \%)$ & $366(50 \%)$ & 0.11 \\
\hline
\end{tabular}




\begin{tabular}{|c|c|c|c|}
\hline Diabetes & $448(35 \%)$ & $260(36 \%)$ & 0.66 \\
\hline Hypertension & $751(58 \%)$ & $459(63 \%)$ & 0.03 \\
\hline Chronic kidney disease & $99(8 \%)$ & $64(9 \%)$ & 0.38 \\
\hline Atrial fibrillation & $78(6 \%)$ & $63(9 \%)$ & 0.03 \\
\hline Family history of premature CVD & $557(43 \%)$ & $330(46 \%)$ & 0.35 \\
\hline Cancer & $61(5 \%)$ & $37(5 \%)$ & 0.76 \\
\hline Heart failure & $34(3 \%)$ & $39(5 \%)$ & 0.002 \\
\hline Liver disease & $28(2 \%)$ & $13(2 \%)$ & 0.54 \\
\hline Aspirin & $726(57 \%)$ & $427(59 \%)$ & 0.31 \\
\hline Other antiplatelet agent & $201(16 \%)$ & $118(16 \%)$ & 0.71 \\
\hline ACE inhibitor & $476(37 \%)$ & $291(40 \%)$ & 0.17 \\
\hline ARB & $287(22 \%)$ & $163(22 \%)$ & 0.95 \\
\hline Beta blocker & $488(38 \%)$ & $298(41 \%)$ & 0.17 \\
\hline Calcium Channel Blocker & $279(22 \%)$ & $170(23 \%)$ & 0.37 \\
\hline Diuretic & $223(17 \%)$ & $158(22 \%)$ & 0.02 \\
\hline Oral Anticoagulant & $83(6 \%)$ & $62(9 \%)$ & 0.08 \\
\hline Spironolactone/Eplerenone & $21(2 \%)$ & $13(2 \%)$ & 0.79 \\
\hline Total Cholesterol, mmol/L* & $5.46 \pm 1.36$ & $5.45 \pm 1.41$ & 0.91 \\
\hline $\mathrm{LDL}-\mathrm{C}, \mathrm{mmol} / \mathrm{L}^{*}$ & $3.34 \pm 1.27$ & $3.34 \pm 1.27$ & 1.00 \\
\hline HDL-C, mmol/L* & $1.31 \pm 0.41$ & $1.33 \pm 0.45$ & 0.46 \\
\hline Non-HDL-C, mmol/L* & $4.13 \pm 1.41$ & $4.11 \pm 1.47$ & 0.76 \\
\hline Triglycerides, $\mathrm{mmol} / \mathrm{L}^{*}$ & $2.02 \pm 1.66$ & $2.00 \pm 1.45$ & 0.76 \\
\hline Statin & $984(77 \%)$ & $551(76 \%)$ & 0.75 \\
\hline High intensity statin & $551(43 \%)$ & $313(43 \%)$ & 0.91 \\
\hline Ezetimibe & $332(26 \%)$ & $179(25 \%)$ & 0.56 \\
\hline High intensity statin + ezetimibe & $144(11 \%)$ & $92(13 \%)$ & 0.32 \\
\hline Bile acid sequestrant & $47(4 \%)$ & $55(8 \%)$ & 0.0001 \\
\hline Fibrate & $41(3 \%)$ & $14(2 \%)$ & 0.10 \\
\hline Niacin & $6(0.5 \%)$ & $2(0.3 \%)$ & 0.72 \\
\hline
\end{tabular}

* Mean \pm standard deviation

Table 1: Clinical Baseline Characteristics and Cardiovascular Medications

During the follow up, the use of ezetimibe increased from approximately $25 \%$ at baseline to over $40 \%$ on visit 3 but remained similar between the two groups (Figure 1) while the use of PCSK9i was higher in patients with private insurance $(31.7 \%$ vs. $21 \%, \mathrm{p}=0.0001)$. The LDL-C level decreased slightly more in private insurance group at visit $2(2.37 \pm 1.28$ vs. $2.52 \pm 1.31, \mathrm{p}=0.0165)$ and visit $3(2.11 \pm 1.17$ vs $2.31 \pm 1.17, \mathrm{p}=0.0012)$.
Proportion of patients achieving the recommended LDL-C level was $42.9 \%$ in private and $39.8 \%(\mathrm{p}=0.2)$ in visit 2 and significantly greater in visit $3(54.0 \%$ vs. $45.5 \%, \mathrm{p}=0.001)$. Private insurance was not an independent predictor of achieving recommended LDL-C level in multivariable analysis (Table 2

\begin{tabular}{|l|c|c|}
\hline Variables & Adjusted Odds Ratio (95\% CI) & P value \\
\hline Private ys Public insurance & $1.01(0.87-1.18)$ & 0.88 \\
\hline Age (per year increase) & $1.01(1.01-1.02)$ & 0.0005 \\
\hline BMI (per unit increase) & $1.01(1.00-1.02)$ & 0.07 \\
\hline Female & $0.62(0.52-0.73)$ & $<.0001$ \\
\hline Coronary artery disease & $1.47(1.25-1.74)$ & $<.0001$ \\
\hline Hypertension & $1.14(0.96-1.35)$ & 0.13 \\
\hline Atrial fibrillation & $1.26(0.95-1.67)$ & 0.10 \\
\hline Heart failure & $0.95(0.63-1.42)$ & 0.79 \\
\hline Diuretic & $0.86(0.70-1.05)$ & 0.13 \\
\hline Statin & $3.02(2.48-3.69)$ & $<.0001$ \\
\hline Ezetimibe & $1.66(1.42-1.95)$ & $<.0001$ \\
\hline PCSK9 inhibitor & $15.12(12.07-18.96)$ & $<.0001$ \\
\hline
\end{tabular}

Table 2: Multivariable analysis to determine factors associated with achieving $L D L-C \leq 2.0 \mathrm{mmol} / \mathrm{L}$ (variables in the model are from Table 1 with $p$ $<0.05$ and lipid lowering agents 


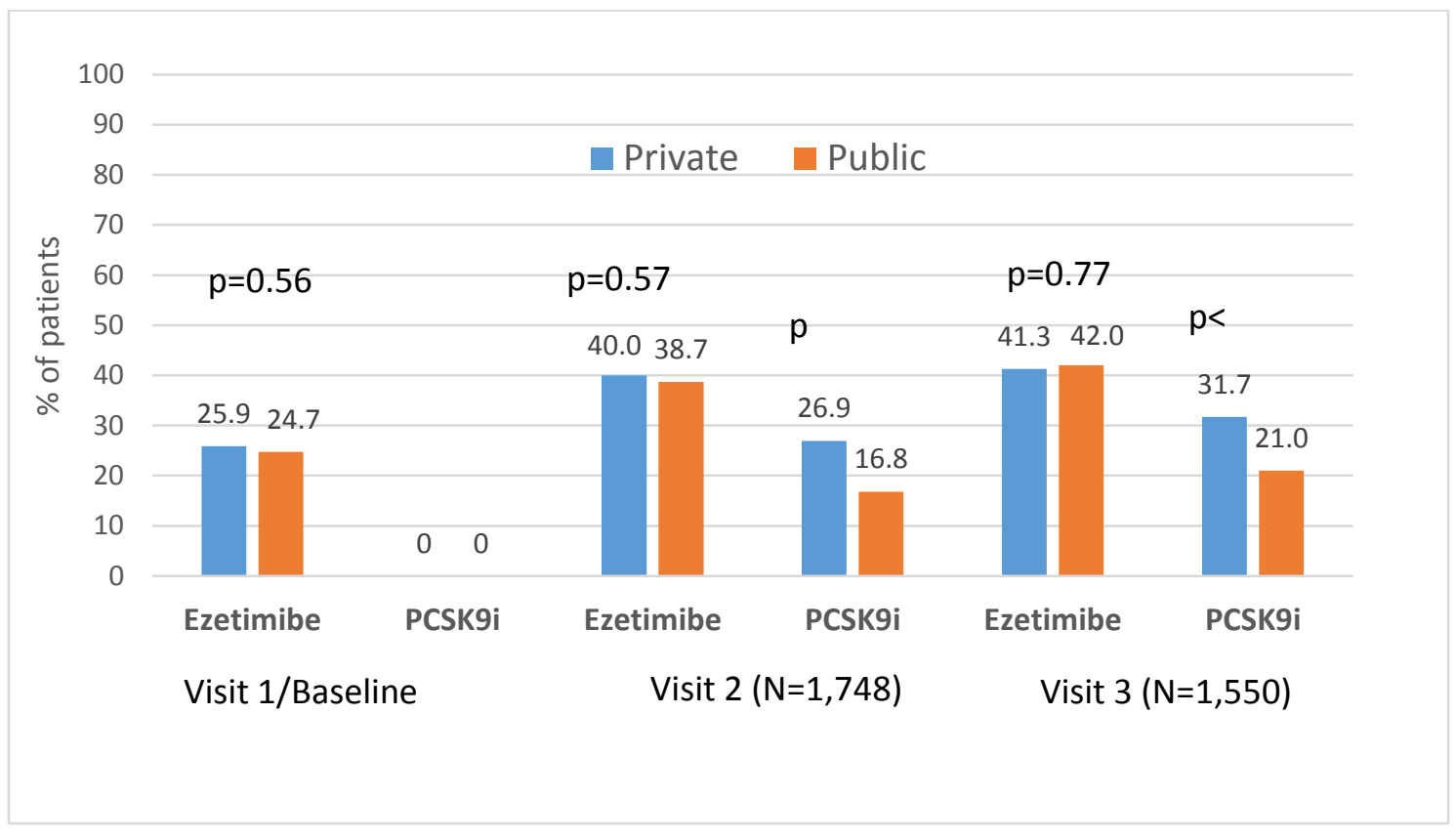

Figure 1: Use of ezetimibe and PCSK9 inhibitor during follow up.

Participating physicians were asked to provide the single most important reason for not being able to follow the guidelines for addition of nonstatin therapy. It is notable that physicians identified cost as an issue for not prescribing more often in patients with public insurance as compared to private insurance for either ezetimibe $(13.5 \%$ vs. $6.6 \%, \mathrm{p}=0.0004)$ or PCSK9i (33.8\% vs. $20.5 \%$, $\mathrm{p}=0.0001)$.

\section{Discussion}

Established CVD and FH are both associated with major adverse cardiovascular morbidity and mortality. Despite the use of high intensity statin therapy, many patients do not achieve the recommended LDL-C level. [10-12] The addition of second and third-line non-statin therapies has been shown to further reduce CV events. [13-15]

We found that the availability of private insurance was associated with a $10 \%$ greater use of PCSK9i but had no impact on the use of genericized high intensity statin or ezetimibe or both. The greater use of PCSK9i was associated with achievement of the recommended LDL-C level as was the use of statin or ezetimibe therapy. However, availability of private insurance was not predictive of better LDL-C target achievement level in multivariable analysis.

The treatment inertia observed in these high-risk patients was more similar than different between the two groups with private and public only insurance, since most of these patients were not on either PCSK9i or ezetimibe by the end of the follow up.

Our prior observations demonstrate benefit of educational intervention on treatment inertia. $[9,16,17]$ Our findings suggest that the availability of private insurance may play a role in achieving the recommended management in lipid lowering but the benefit of private insurance is modest and the cost of medications itself is not a factor in physicians' ability to follow the guideline recommended therapy. These findings are consistent with our prior observations on guidelines-oriented management of diabetes mellitus in Canada. [18] Accordingly, other factors may be important. For example, private insurance coverage may vary across Canada with respect to coverage of conditions such as FH. In addition, it is not uncommon for access with or without private insurance to require filling of multiple forms, sometimes multiple times, thereby leading to some inertia irrespective of private coverage. This may account for the improved but less than expected uptake of PCSK9 inhibitors in patients with private coverage. This and other barriers that impair achievement of an LDL-C treatment goal may require fuller exploration from both the perspective of patients as well as treating physicians.

\section{Limitations}

This post-hoc analysis is subject to physician and patient selection bias. Physicians invited to participate had prior experience in similar programs and therefore may not be representative of all Canadian health care providers. The extent of the care gap detected, and low use of statin and non-statin therapy argues against selection bias of physicians skilled in the LDL-C management.

While these selection biases may limit the generalizability of our findings, they in no way diminish the validity of our conclusions about the existence of the treatment inertia and only modest impact of private insurance in lipid lowering therapy.

\section{Conclusion}

While PCSK9i use was higher in patients with private insurance, the majority of patients with either private or public insurance experienced similar treatment inertia. The cost of medications does not appear to be the dominant reason for care gap in lipid lowering of higher risk patients. 


\section{DISCLOSURES:}

$\mathrm{AL}$ has received on behalf of the Canadian Heart Research Centre research grant support from Actelion, Amgen, Astra-Zeneca, Bayer, BMS, Merck, Novo Nordisk, Pfizer, Servier and Sanofi.

LAL has received research grant support from Astra Zeneca, Amgen, Kowa, The Medicines Company, Novartis, and Sanofi. He has also served as a consultant for Astra Zeneca, Amgen, Esperion, HLS, Merck, The Medicines Company, Novartis, and Sanofi

JG has received speaker/consulting honoraria from Amgen, AstraZeneca, Bayer, Boehringer Ingelheim, Bristol Myers Squibb, Eli Lilly, Ferring Pharmaceuticals, HLS Therapeutics, Janssen/Johnson \& Johnson, Merck, Novartis, Novo Nordisk, Pfizer, Sanofi, Servier, Sunovion;

SGG has received research grant support (e.g., steering committee or data monitoring committee) and/or speaker/consulting honoraria (e.g., advisory boards) from: Amgen, AstraZeneca, Bayer, Boehringer Ingelheim, Bristol Myers Squibb, CSL Behring, DaiichiSankyo/American Regent, Eli Lilly, Esperion, Ferring Pharmaceuticals, GlaxoSmithKline, HLS Therapeutics, Janssen/Johnson \& Johnson, Merck, Novartis, Novo Nordisk A/C, Pendopharm, Pfizer, Regeneron, Sanofi, Servier; and salary support/honoraria from the Heart and Stroke Foundation of Ontario/University of Toronto (Polo) Chair, Canadian Heart Research Centre and MD Primer, Canadian VIGOUR Centre, Duke Clinical Research Institute, New York University Clinical Coordinating Centre, and PERFUSE Research Institute

JAS has received research support from Sanofi and has served as a consultant and/or speaker for AstraZeneca, Amgen, Bayer, HLS Therapeutics Lilly, and Novartis.

Mary Tan has no disclosures.

\section{References}

1. Baigent C, Keech A, Kearney PM, et al; Cholesterol Treatment Trialists (CTT) Collaborators. Efficacy and safety of cholesterol-lowering treatment: prospective meta-analysis of data from 90,056 participants in 14 randomised trials of statins. Lancet 2005;366:1267-1278.

2. Anderson TJ, Gregoire J, Pearson GJ et al. 2016 Canadian Cardiovascular Society Guidelines for the Management of Dyslipidemia for the Prevention of Cardiovascular Disease in the Adult. Can J Cardiol 2016;32:1263-1282.Pearson TA, Laurora I,

3. Brunham LR, Ruel I, Aljenedil S, et al. Canadian Cardiovascular Society Position Statement on Familial Hypercholesterolemia: Update 2018. Can J Cardiol 2018;34:1553-1563.

4. Saposnik G, Goodman SG, Leiter LA, et al. Applying the evidence: Do patients with stroke, coronary artery disease, or both achieve similar treatment goals? Stroke 2009;40:14171424.

5. Hackam DG, Leiter LA, Yan AT, et al. Missed opportunities for secondary prevention of cardiovascular disease in Canada. Can J Cardiol 2007; 23:1124-1130.
6. Yan AT, Yan RT, Tan M, et al. Contemporary management of dyslipidemia in high-risk patients: targets still not met. Am J Med 2006;119:676-683.

7. Petrella RJ, Merikle E, Jones J. Prevalence and treatment of dyslipidemia in Canadian primary care: a retrospective cohort analysis. Clin Ther 2007;29: 742-750.

8. Rapezzi C, Biagini E, Bellis P, et al. Exploring the gap between National Cholesterol Education Program guidelines and clinical practice in secondary care: results of a cross-sectional study involving over 10000 patients followed in different specialty settings across Italy. J Cardiovasc Med 2008; 9:878-887.

9. Langer A, Tan M, Goodman SG, Gregoire J, Lin PJ, Mancini GBH, Stone JA, Wills C, Spindler C, Leiter LA GOAL Canada: Physician Education and Support Can Improve Patient Management CJC Open 2020;2:49-54.

10. Martineau P, Gaw A, de Teresa E, et al. Effect of individualizing starting doses of a statin according to baseline LDL-cholesterol levels on achieving cholesterol targets: the Achieve Cholesterol Targets Fast with Atorvastatin Stratified Titration (ACTFAST) study. Atherosclerosis 2007;191:135146.

11. Leiter LA, Berard L, Bowering K, et al. Type 2 Diabetes Mellitus Management in Canada: Is It Improving? Can J Diabetes 37 (2013) 82e89

12. Goodman SG, Langer A, Bastien NR, et al. Prevalence of dyslipidemia in statin treated patients in Canada: results of the Dyslipidemia International Study (DYSIS). Can J Cardiol 2010;26:e330e5.

13. Cannon CP, Blazing MA, Giugliano RP, et al. Ezetimibe added to statin therapy after acute coronary syndromes. The New England journal of medicine. 2015

14. Sabatine MS, Giugliano RP, Keech AC et al. Evolocumab and Clinical Outcomes in Patients with Cardiovascular Disease. N Engl J Med 2017;376:1713-1722

15. Schwartz GG, Szarek M, Bhatt DL et al. The ODYSSEY OUTCOMES Trial: Topline Results. Alirocumab in Patients After Acute Coronary Syndrome. Presented at the American College of Cardiology Annual Scientific Sessions March 10, 2018

16. Langer A, Tan M, Cieza $\mathrm{T}$ et al. Can Clinical Reminder Help Optimize the Use of Secondary Prevention Therapies in NonST Elevation Acute Coronary Syndrome? Int J Cardiol Cardiovasc Med 2017;1:1-5.

17. Katz PM, Mendelsohn AA, Goodman SG, Langer A, Teoh H, Leiter LA, Use of a Treatment Optimization Algorithm Involving Statin-Ezetimibe Combination Aids in Achievement of Guideline-Based Low-Density Lipoprotein Targets in Patients With Dyslipidemia at High Vascular Risk GuidelineBased Undertaking to Improve Dyslipidemia Management in Canada (GUIDANC). Can J of Cardiol; 2011(27):138-145.

18. Teoh H, Braga MFB, Casanova A, et al. Time 2 Do More Quality Enhancement Research Initiative (T2DM QUERI): Patient age, ethnicity, medical history and risk factor profile, but not drug insurance coverage, predict successful attainment of glycemic targets. Diabetes Care 2010;33(12):2558-2560. 
To Submit Your Article Click Here: Submit Manuscript

DOI: $10.31579 / 2641-0419 / 154$
Ready to submit your research? Choose Auctores and benefit from:

* fast, convenient online submission

* rigorous peer review by experienced research in your field

* rapid publication on acceptance

* authors retain copyrights

* unique DOI for all articles

* immediate, unrestricted online access

At Auctores, research is always in progress.

Learn more www.auctoresonline.org/journals/clinical-cardiology-andcardiovascular-interventions 